\title{
Proportion Design Method and Water Stability of Cement- Emulsified Asphalt Cold Recycling Mixtures
}

\author{
Junxiao $\mathrm{Li}^{1{ }^{1},}$, Wei $\mathrm{Fu}^{2}$ and Xiaobo Yin ${ }^{3}$ \\ ${ }^{1}$ Institute of 0ceanographic Instrmentation, Qilu University of Technology (Shandong Academy of Sciences), Shandong Provincial Key \\ Laboratory of Marine monitoring instrument equipment technology, National Engineering and Technological Research Center of Marine \\ Monitoring Equipment, Qingdao 266001, China \\ ${ }^{2}$ Dept. of No.2 sanatorium, Navy Qingdao No.1 Sanatorium of PLA, Qingdao 266001, China \\ ${ }^{3}$ Zhuhai Dacheng Engineering Testing Co. Ltd, Zhuhai 519000, China
}

\begin{abstract}
Nowadays, a large amount of work has been done in the field of emulsified asphalt cold regeneration. Three different proportions of emulsified asphalt cold recycling mixtures were designed by mixing different ratios of new aggregates and RAP, the effect of cement content and RAP content on the mixtures's water stability was studied. The results show that the addition of cement can improve the mixtures's water stability, but there is an optimum content; the mixtures's water stability reduces with the increase of RAP content.
\end{abstract}

\section{Introduction}

In china, the total number of highways was $4,773,500$ kilometers by the end of 2017. Asphalt road occupies $76 \%$ in high-grade road construction, so there will be a large amount of recycled asphalt mixture in the road pavement renovation, renovation and conservation every year. If calculate by $10 \%$ of highway pavement need repair, there will be 2.2 million tons recycled asphalt mixture every year. It is easy to be predicted that more and more recycled asphalt mixture will be generated in the future. The recycled asphalt mixture was treated as waste in some engineering projects, which is a waste of resources. In addition, they will occupy a lot of land, and pollute the environment. Asphalt cold recycling can be a good solution, which can make the old pavement materials reused and save $40 \%-50 \%$ of the total investment ${ }^{[1,2,3]}$.In recent years, the cold regeneration technique of recycled waste road materials by foam asphalt has been famous for its remarkable advantages in energy saving, environmental protection and economy. Nowadays, a large amount of work has been done in the field of emulsified asphalt cold regeneration ${ }^{[4,5]}$.

The effect of emulsified asphalt cold regeneration is influenced by many factors, such as the type and amount of emulsified asphalt, the gradation of the mixture, the dosage of the new aggregate, and the dosage of the cement. Based on the different proportions of RAP and new aggregate expected to cooperate, three kind of emulsified asphalt cold recycled mixture were designed. The optimum water consumption of the mixture was determined by the compaction test. By designing the proportion of emulsified asphalt cold recycled mixture combined with the water stability experiment, for this mixture the best proportion are determined. The results of this study can provide some reference for the design of practical emulsified asphalt cold regeneration project.

\section{Raw materials}

Table 1. Gradation of RAP and new mixture.

\begin{tabular}{|c|c|c|c|c|}
\hline \multirow{2}{*}{$\begin{array}{c}\text { Mesh size } \\
\text { /mm }\end{array}$} & \multicolumn{4}{|c|}{ Pass rate /\% } \\
\cline { 2 - 5 } & RAP & $\begin{array}{c}\text { 1\# new } \\
\text { mixture }\end{array}$ & $\begin{array}{c}\text { 2\# new } \\
\text { mixture }\end{array}$ & $\begin{array}{c}\text { 3\# new } \\
\text { mixture }\end{array}$ \\
\hline 26.5 & 100.00 & 100.00 & 100 & 100 \\
\hline 19.00 & 98.87 & 98.55 & 100 & 100 \\
\hline 16.00 & 96.82 & 93.33 & 100 & 100 \\
\hline 13.20 & 92.75 & 69.27 & 100 & 100 \\
\hline 9.50 & 86.69 & 21.64 & 100 & 100 \\
\hline 4.75 & 73.00 & 0.07 & 99.82 & 100 \\
\hline 2.36 & 51.49 & 0.02 & 74.92 & 100 \\
\hline 1.18 & 36.02 & 0.00 & 59.78 & 100 \\
\hline 0.60 & 19.94 & 0.00 & 46.11 & 100 \\
\hline 0.30 & 4.67 & 0.00 & 28.43 & 100 \\
\hline 0.15 & 1.38 & 0.00 & 19.45 & 100 \\
\hline 0.075 & 0.36 & 0.00 & 13.24 & 95.54 \\
\hline
\end{tabular}

The recycled asphalt pavement (RAP) is from highway milling material in Wuhan, China. As for the role of RAP in cold regenerated mixture, there is still no consensus in academia. In this study, RAP is regarded as the black aggregates, and the mechanism of aging

* Corresponding author: caike0501@163.com 
asphalt in the process of cold regeneration is not considered. Simply using RAP as the regenerated mixture aggregates can't meet the design requirements. So, the new materials used in this study are of three kinds, which are limestone and their technical indexes meet the specification requirements. Table 1 is Gradation of RAP and new mixture. Emulsified asphalt is homemade cationic emulsified asphalt. Table 2. is its technical indicators. Cement is P.O. 425 ordinary Portland cement from Huaxin cement factory, and table 3 . is its chemical composition. Water is just general water.

Table 2. Technical indicators of emulsified asphalt.

\begin{tabular}{|c|c|c|c|}
\hline \multicolumn{2}{|r|}{ Test item } & Quality requirements & Testing result \\
\hline \multicolumn{2}{|r|}{ Demulsification velocity } & Slow crack or Medium speedcrack & Slow crack \\
\hline \multicolumn{2}{|r|}{ Particle charge } & Cationic $(+)$ & Cationic \\
\hline \multicolumn{2}{|r|}{$1.18 \mathrm{mmsieving}$ residue $(\%)$} & $\leq 0.1$ & 0.027 \\
\hline \multicolumn{2}{|r|}{ His viscosityE25 } & $2 \sim 30$ & 10.5 \\
\hline \multirow{4}{*}{$\begin{array}{l}\text { Evaporation } \\
\text { residue }\end{array}$} & Residual content of points(\%) & $\geq 62$ & 63.4 \\
\hline & solubility $(\%)$ & $\geq 97.5$ & 99.2 \\
\hline & $25^{\circ} \mathrm{C}$ penetration $(0.1 \mathrm{~mm})$ & $50 \sim 300$ & 69.5 \\
\hline & $15^{\circ} \mathrm{C}$ ductility $(\mathrm{cm})$ & $\geq 40$ & $>100$ \\
\hline \multicolumn{2}{|c|}{ Wrapped with coarse aggregate area } & $\geq 2 / 3$ & $>3 / 4$ \\
\hline \multicolumn{2}{|c|}{ Coarse aggregate and Fine aggregate mixing experiments } & uniform & uniform \\
\hline $\begin{array}{l}\text { Room } \\
\text { temperature } \\
\text { storage } \\
\text { stability }(\%)\end{array}$ & $\begin{array}{l}1 \mathrm{~d} \\
5 \mathrm{~d}\end{array}$ & $\begin{array}{l}\leq 1 \\
\leq 5\end{array}$ & $\begin{array}{c}0.50 \\
1.0\end{array}$ \\
\hline
\end{tabular}

Table 3. Technical indicators of emulsified asphalt.

\begin{tabular}{|c|c|}
\hline $\begin{array}{c}\text { Chemical } \\
\text { composition }\end{array}$ & Content $/ \%$ \\
\hline $\mathrm{SiO}_{2}$ & 21.73 \\
\hline $\mathrm{Al}_{2} \mathrm{O}_{3}$ & 4.25 \\
\hline $\mathrm{Fe}_{2} \mathrm{O}_{3}$ & 2.67 \\
\hline $\mathrm{CaO}$ & 63.59 \\
\hline $\mathrm{MgO}$ & 2.21 \\
\hline $\mathrm{Na}_{2} \mathrm{O}$ & 0.55 \\
\hline $\mathrm{SO}_{3}$ & 2.39 \\
\hline Ignition loss & 1.75 \\
\hline
\end{tabular}

\section{Design for proportion of cement- emulsified asphalt cold recycled mixture}

\subsection{Gradation design}

There are a lot of specifications for the gradation design of cold recycled mixture, but there is no uniform standard. The grading design of this study is based on the $<$ Technical Specification for Road Asphalt Pavement Regeneration> (JTG F41-2008). Mixture 1, Mixture 2, and Mixture 3 were three different proportions of emulsified asphalt cold recycling mixtures that were designed by mixing different ratios of new aggregates and RAP.

Mixture $1=25 \% \mathrm{RAP}+40 \% 1$ \#new mixture $+35 \% 2 \#$ new mixture;
Mixture $2=50 \% \mathrm{RAP}+25 \% 1$ \#new mixture $+25 \% 2 \#$ new mixture;

Mixture $3=75 \% \mathrm{RAP}+15 \% 1 \#$ new mixture $+5 \% 2 \#$ new mixture $+5 \% 3$ \# new mixture.

Each of the three gradations meets the requirements of the medium-grain grading of $<$ Technical Specification for Road Asphalt Pavement Regeneration> (JTG F412008). Fig.1. is cold recycling mixtures gradation curves which compared with the standard grading.

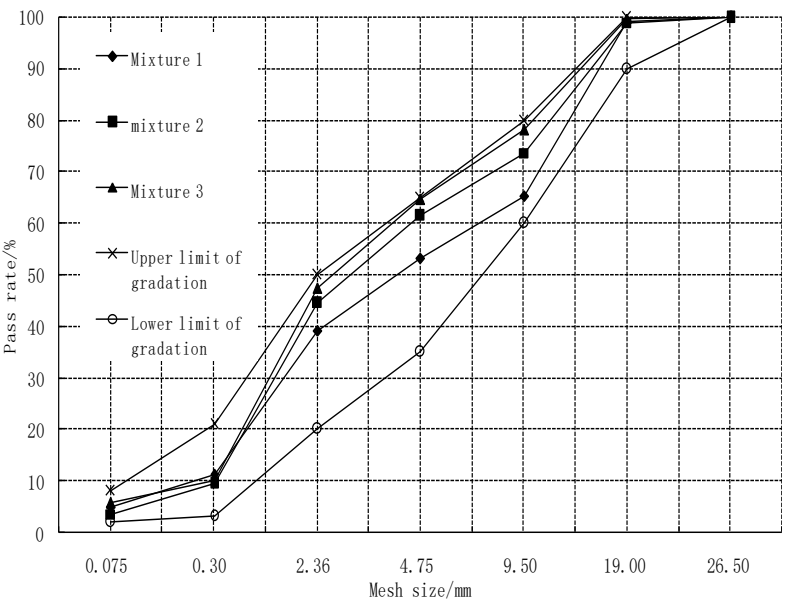

Fig. 1. Cold recycling mixtures gradation curves.

\subsection{The amount of cement and emulsified asphalt}

Cement is only used as a stabilizer and it is not considered as active filler, regardless of its effect on the mixture grading. In order to investigate the effect of cement content change on the stability of mixed material water, this study set five kinds of cement content, which are $0 \%, 1 \%, 2 \%, 3 \%$ and $4 \%$ of the RAP and new mixture 
total quality. The amount of emulsified asphalt is $4.2 \%$ of the RAP and new mixture total quality.

\subsection{The amount of cement and emulsified asphalt}

Mix and mix well and need a moderate amount of water. If the water is too little, the emulsified asphalt is difficult to disperse, and the lubrication between the aggregate particles is not enough. It is difficult to compaction the mixture and the cement cannot be fully hydrated. If there is too much water, the pressure of moving water will increase, and the mixture will be hard to compaction. At the same time, emulsified asphalt and cement slurry loss. Hydrate crystal development is not sufficient, and health time is long, and material strength is low. Therefore, it is necessary to determine the optimum mixing water consumption through experiments.

The amount of emulsified asphalt is $4.2 \%$ of the RAP and new mixture total quality. The optimized amount of water (OWC) used and the maximum dry density were determined by the compaction test, and the mixing water consumption is calculated. The impaction test was referring to the method in $<$ Highway Engineering stable inorganic binder materials testing procedures $>$ (JTG E 51-2009). The RAP and new aggregates used in this experiment were air-dried, which could be considered as $0 \%$ water content. Therefore, the added amount of water is equal to the difference value between the OWC of the mixture and the water content of the asphalt emulsion. Table 4 shows the total amount of mixed materials and the maximum dry density obtained by the compaction test, and calculates the actual amount of water needed in the experiment.

Table 4. Compaction test results.

\begin{tabular}{|c|c|c|c|c|}
\hline \multirow{3}{*}{$\begin{array}{c}\text { Type of } \\
\text { mixture }\end{array}$} & $\begin{array}{c}\text { Cement } \\
/ \%\end{array}$ & $\begin{array}{c}\text { OWC/ } \\
\%\end{array}$ & $\begin{array}{c}\text { Maximum } \\
\text { dry density } \\
/ \mathrm{g} \cdot \mathrm{cm}^{-3}\end{array}$ & Water/\% \\
\hline \multirow{4}{*}{1} & 0 & 6.02 & 2.04 & 4.42 \\
\cline { 2 - 5 } & 1 & 6.48 & 2.14 & 4.88 \\
\cline { 2 - 5 } & 2 & 6.69 & 2.09 & 5.09 \\
\cline { 2 - 5 } & 3 & 6.90 & 2.11 & 5.30 \\
\hline \multirow{4}{*}{2} & 4 & 7.01 & 2.19 & 5.41 \\
\cline { 2 - 5 } & 0 & 6.14 & 2.19 & 4.54 \\
\cline { 2 - 5 } & 1 & 6.47 & 2.08 & 4.87 \\
\cline { 2 - 5 } & 2 & 6.68 & 2.21 & 5.08 \\
\cline { 2 - 5 } & 3 & 6.97 & 2.14 & 5.15 \\
\hline \multirow{4}{*}{3} & 4 & 7.09 & 2.16 & 5.49 \\
\cline { 2 - 5 } & 0 & 6.09 & 2.09 & 4.49 \\
\cline { 2 - 5 } & 1 & 6.39 & 2.07 & 4.79 \\
\cline { 2 - 5 } & 2 & 6.58 & 2.18 & 4.98 \\
\cline { 2 - 5 } & 3 & 6.74 & 2.12 & 5.14 \\
\hline & 4 & 6.95 & 2.20 & 5.35 \\
\hline
\end{tabular}

\section{Evaluation of water stability of cold recycling mixtures}

\subsection{Test method}

This experiment adopts wet splitting strength and dry splitting strength ratio at $15{ }^{\circ} \mathrm{C}$ to evaluate the water stability of mixture. The impaction test was referring to the method in $<$ Highway Engineering stable inorganic binder materials testing procedures $>$ (JTG E 51-2009) the preparation of mixture standard Marshall Specimens was refer to the methods in $<$ Road engineering asphalt and asphalt mixture test procedure $>$ (JTG 052-2000). After demoulding, specimens kept in $60{ }^{\circ} \mathrm{C}$ ventilation oven by $72 \mathrm{~h}$ curing. This curing method can simulate the condition after $10 \mathrm{~d}$ actual pavement construction. Splitting test: Specimens at $15^{\circ} \mathrm{C}$ environment after $1.5 \mathrm{~h}$ do dry splitting test; After specimens soak in $25{ }^{\circ} \mathrm{C}$ constant temperature water bath $23 \mathrm{~h}$, then in $15{ }^{\circ} \mathrm{C}$ constant temperature water bath for $1 \mathrm{~h}$, do wet splitting test at $15{ }^{\circ} \mathrm{C}{ }^{[6]}$.

\subsection{The effect of cement dosage on the water stability of mixture}

Fig. 2 shows the variation of the dry splitting strength and wet splitting strength of the three mixtures respectively under different cement content.

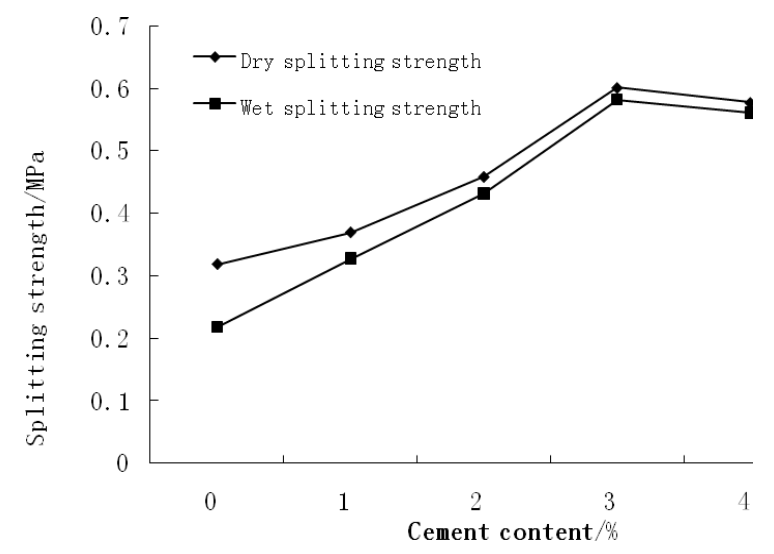

(a)Mixture 1

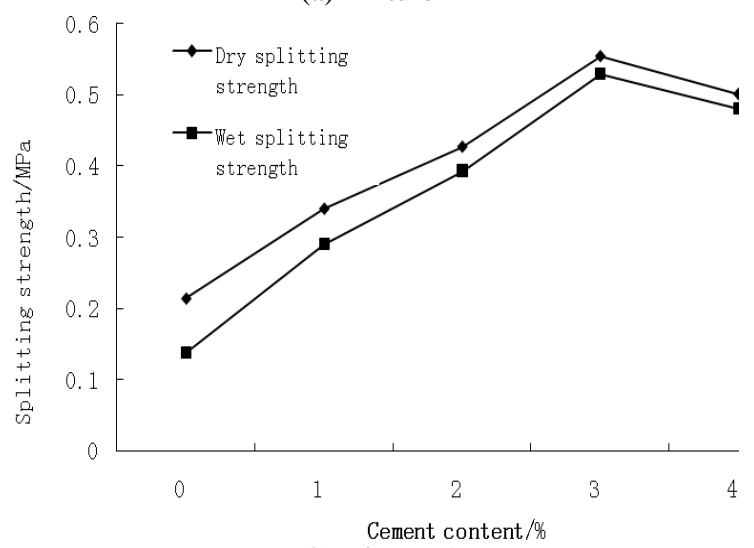

(b)Mixture 2 


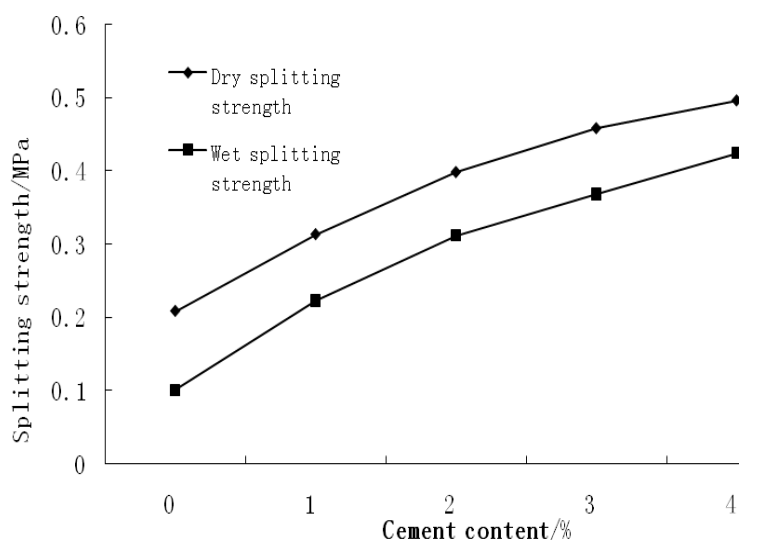

(c)Mixture 3
Fig. 2. The relationship between splitting strength and cement content.

It can be seen from Fig. 2. that the dry splitting strength and wet splitting strength of the mixture 3 are increased with the increase of cement content. When the cement content is less than 3\%, the dry splitting strength and wet splitting strength of $\mathrm{A}$ and $\mathrm{B}$ increase with the increase of cement content.

Table 5. is the water stability of different cement content mixtures. As shown in table 5, for certain types of mixtures, the water stability increases with the increase of cement content. When comparing $1 \%$ cement content and $0 \%$ cement content, the increase of water stability of the three mixed materials was $20.3 \%, 20.8 \%$ and $22.6 \%$ respectively. Therefore, the addition of cement to the water stability of the mixture is very obvious.

Table 5. Water stability of different cement content mixtures

\begin{tabular}{|c|c|c|c|c|c|c|}
\hline $\begin{array}{c}\text { Mixture } \\
\text { type }\end{array}$ & $\begin{array}{c}\text { Cement } \\
\text { content } \\
/ \%\end{array}$ & 0 & 1 & 2 & 3 & 4 \\
\hline $\begin{array}{c}\text { Mixture } \\
1\end{array}$ & \multirow{3}{*}{$\begin{array}{l}\text { Dry and } \\
\text { wet } \\
\text { splitting } \\
\text { strength } \\
\text { ratio. }\end{array}$} & 0.684 & 0.887 & 0.941 & 0.967 & 0.970 \\
\hline $\begin{array}{l}\text { Mixture } \\
2\end{array}$ & & 0.646 & 0.854 & 0.921 & 0.955 & 0.961 \\
\hline $\begin{array}{c}\text { Mixture } \\
3\end{array}$ & & 0.488 & 0.714 & 0.785 & 0.804 & 0.855 \\
\hline
\end{tabular}

After the hydration of the cement in cold cycling mixture, some of the hydration products $\mathrm{C}_{4} \mathrm{AH}_{13}$ react with gypsum: $\mathrm{C}_{4} \mathrm{AH}_{13}+3 \mathrm{C}-\mathrm{S}-\mathrm{H}_{2}+14 \mathrm{H}=\mathrm{AFt}+\mathrm{CH}$. The needle bar AFt will be filled space within the mix and form a network structure that increased mixture strength. Others hydration products $\mathrm{C}-\mathrm{S}-\mathrm{H}$ coagulation forms a fibrous structure that further increased mixture strength ${ }^{[7]}$. Hydration products develop to the surrounding space of the cement particles, criss-cross, and gradually fill the mix of all the capillary space. Thereby it forms a uniform, dense, pore closed the whole structure, and enhances the overall strength of the mixture of water and anti-damaging. On the other hand, the crystal structure of cement hydration products can be formed and developed in the water phase of asphalt emulsion. The cement hydration products and the released asphalt after emulsion breaking are intertwined, and the mixture is tightly integrated into a whole. Under the combined action of these two aspects, the splitting strength and water stability of the mixture are improved with the increase of cement content. However, cement content is not the higher the better ${ }^{[8]}$. Because the increase of cement dosage will lead to the increase of the dry shrinkage of the mixture, resulting in a severe shrinkage crack to reduce the strength. This is the reason that when the cement content is $4 \%$, the strength of Mixture 2 and Mixture 3 is slightly lower than that of $3 \%$ cement. Therefore, the optimal cement dosage for this test was $3 \%$.

\subsection{The effect of RAP dosage on the water stability of mixture}

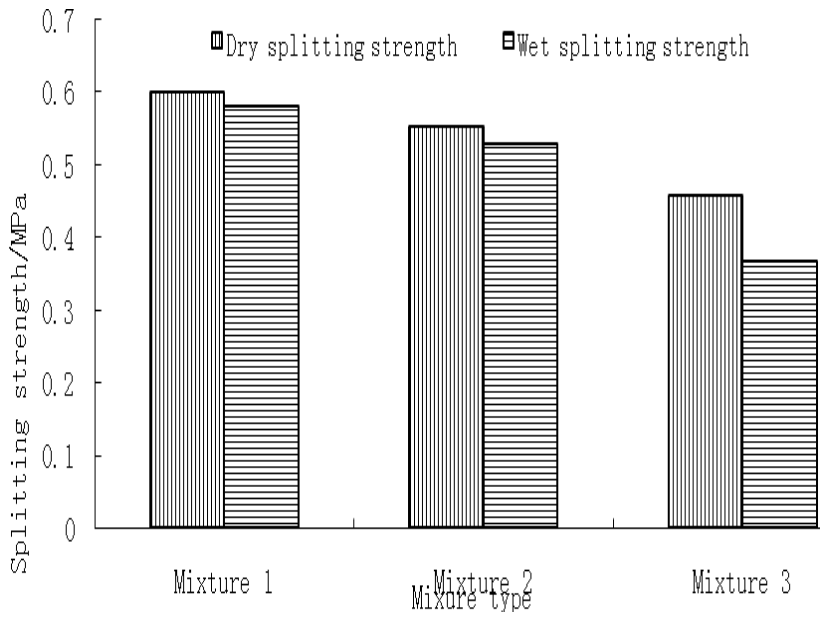

Fig.3. Cold recycling mixtures gradation curves.

When the cement content was selected as $3 \%$, the dry and wet splitting strength values of the three mixed materials were compared, and the results were shown in Fig. 3.

The RAP dosage of mixture 1, mixture 2 and mixture 3 was $25 \%, 50 \%$ and $75 \%$ respectively. As shown in Fig. 3 , with the increase of RAP proportion in the mixture, the dry and wet splitting strength of the mixture decreased gradually. The dry and wet splitting strength of the three kinds of mixtures was $0.967,0.955$ and 0.804 respectively. But $25 \%$ RAP content is only $1.2 \%$ higher than the 50\% RAP content that is 16.3 percent larger than the $75 \%$ RAP mixture. This is due to the fact that as the amount of RAP increases, the content of stone debris in the mixture will be reduced. Thus, the adhesion of aggregates and emulsified asphalt is weakened, and the dry, wet splitting strength and water stability of the mixture are reduced. However, due to the cementation effect of cement, the amount of RAP content increased from $25 \%$ to $50 \%$, the reduction of the mixture splitting strength and water stability were minor. The cementation of cement is not sufficient to compensate the strength of the loss due to the attenuation of aggregates and emulsified asphalt, when the amount of RAP in the mixture is further increased. The results show that the mixture drying, wet splitting strength and water stability are greatly reduced.

In the actual cold regeneration construction, the lower the new aggregate amount in the mixture, the 
lower the material cost. But the higher the RAP dosage, the worse the performance of the mixture. Considering the factors of these two aspects, this experiment determines that the Mixture 2 is the optimal gradation.

\section{Conclusions}

By adding new aggregates of certain amount and granule, it can be combined with recycled asphalt pavement materials (RAP) to meet the design requirements. The design of the emulsion asphalt cold regenerated mixture gradation meets <Technical specification for road asphalt pavement regeneration $>$ (JTG F41-2008).

The addition of cement can significantly improve the splitting strength and water stability of emulsified asphalt cold regeneration mixture. However, the high cement content will cause serious shrinkage crack in the mixture, which will reduce the strength of the mixture.

With the increase of RAP dosage, the splitting strength and water stability of the mixture were reduced. Compared with the mixture of $25 \%$ RAP content, the mixture of $50 \%$ RAP, mixture of $25 \%$ RAP has a small reduction in splitting strength and water stability. Compared with the mixture of $25 \%$ RAP content, the mixture of $75 \%$ RAP, mixture of $75 \%$ RAP has a big reduction in splitting strength and water stability.

The best mixture ratio of this study is the Mixture 2 $(50 \% \mathrm{RAP}+25 \% 1$ \#new mixture $+25 \% 2 \#$ new mixture), and the cement content is $3 \%$, and the emulsified asphalt content is $4.2 \%$, and the water content is $5.15 \%$. Best of proportion of mixture of $15^{\circ} \mathrm{C}$ dry splitting strength is $0.554 \mathrm{MPa}$, and wet splitting strength is $0.529 \mathrm{MPa}$, and dry wet splitting strength ratio 0.955 . All these meet the requirements of the design of the emulsified asphalt cold regeneration mixture.

\section{References}

1. Wang Guo-ke, Zhou Zhi-li, Foamed Asphalt Cold in-plant Recycling Applied in Pavement, Reconstruction Transport Standardization, 219 (2010)

2. Guidelines for Cold In-Place Recycling, Asphalt Recycling and Reclaiming Association, Annapolis, MD, (1991)

3. Murphy DT, Emery JJ. Modified cold in-place asphalt recycling. Transportation Research Record, Washington, D.C., (1996)

4. Wang Dengzhou, Wang Ler, Zhao Yongbo, Study on the design method of emulsified asphalt cold regeneration mixture,Journal of China \& Foreign Highway, 29,2(2009),

5. Zhong Mengwu, $\mathrm{Wu}$ Chaofan, $\mathrm{Yu}$ Yongsheng, Study on the design method of emulsified asphalt mixture with cement.Road, 1 (2008)

6. Fang zhi SHI, Xiu jun LI, Da quan SUN, Wei min LV. Discussion About Design Methods for Recycling Cold Mix Asphalt.Highway, 11 (2004)

7. Yuan Yunzhang, Gelling Material Science (Wuhan University of Technology Press, 2008)

8. Xiaobo Yin: Performance of Emulsified Asphalt Full Thickness Cold Recycling Subgrade Materials, Advanced Materials Research, (2014) 